\title{
New medical marijuana regulations shift onus to doctors to prescribe
}

$\mathrm{H}$ ealth Canada's new medical marijuana regulations shift the onus from federal regulators to doctors and nurse practitioners to write "medical documents" similar to prescriptions authorizing patients to obtain marijuana from a federally licensed provider.

Under the previous program, the federal government provided a list of federally sanctioned medical conditions that would qualify a patient for medical marijuana. Doctors filled out a form confirming their patients' medical conditions and Health Canada issued an authorization to possess marijuana.

Under the new "Marihuana for Medical Purposes Regulations," published in the Canada Gazette on June 19, Health Canada's role will be limited to licensing marijuana providers. Doctors and nurse practitioners will decide which patients are eligible and what dose is appropriate. The new regulations will be fully implemented by Mar. 31, 2014. According to its website, Health Canada will "soon" release updated information on marijuana for health care professionals, including a summary of the peerreviewed literature on potential therapeutic uses and harmful effects.

Both the Canadian Medical Association and the Federation of Medical Regulatory Authorities of Canada have opposed the regulatory changes that will see physicians prescribing marijuana, and the Canadian Pharmacists Association is calling for "evidencebased information" to support prescribing and dispensing medical marijuana.

"Asking physicians to prescribe drugs that have not been clinically tested runs contrary to their training and ethics," Dr. Anna Reid, president of the Canadian Medical Association, said in a news release. "Marijuana is a complex substance with strains that vary greatly in power and effect, but we have no information on potency, dosage or how it interacts with other therapies."

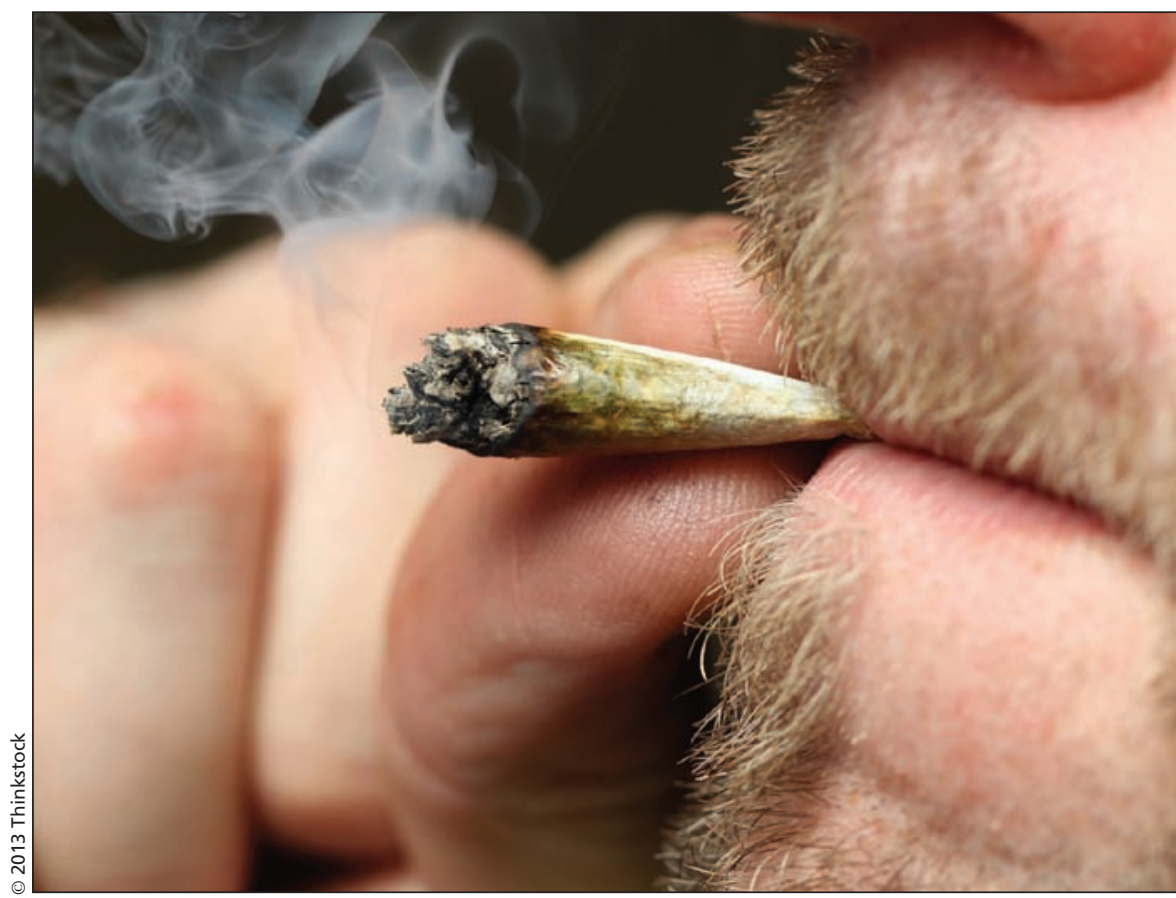

Both the Canadian Medical Association and the Federation of Medical Regulatory Authorities of Canada have opposed the regulatory changes that will see physicians prescribing marijuana.

Marijuana has "a huge potential to cause harm," Reid added. She is concerned that with the federal government abdicating its role in the program, "there is no one to certify that the drug will not harm the patient."

"Patients would not want us to prescribe drugs for heart disease, cancer or any other illness without the scientific evidence to back those drugs up. Why does the federal government want us to do so with marijuana?" Reid asked.

Despite the important change in what doctors are being asked to do, Health Canada has not responded to concerns from the CMA or the Federation of Medical Regulatory Authorities of Canada.

Dr. Heidi Oetter, past-president of the federation wrote a letter to Health Canada in February and is calling on Aglukkaq to meet medical representatives' in person (www.fmrac.ca/SubmissiononMedical Marihuana.pdf).
"It's an abdication of the responsibility of Health Canada," says Oetter. "We would have thought there was a role for people who regulate the practice of medicine to have their legitimate concerns expressed. That should have included an opportunity to meet face-toface with the federal minister of health."

The new regulations "aim to treat marihuana as much as possible like other narcotics used for medical purposes," Health Canada says. But the physician groups say marijuana is not like the other drugs doctors prescribe because it has not been examined in clinical trials and there are no data on dosing or adverse effects available.

The federation believes that the physician's role should be limited to attesting to the medical condition, as was the case under the old program.

"This would avoid the clinical and regulatory challenges physicians would face in prescribing a substance like 
marihuana that is not an approved drug, narcotic or otherwise," the letter states.

Health Canada should either approve marijuana as a therapeutic product, like any other drug, or leave doctors' roles as they were previously, the federation urges.

The new regulations also allow doctors, nurse practitioners and hospitals to accept marijuana on behalf of their patients and dispense it.

Approximately 30000 people now participate in Health Canada's Mari- huana Medical Access Program, many of whom grow marijuana in their homes. Under the new regulations, production of medical marijuana will shift to licensed facilities and will be "produced under secure and sanitary conditions," Health Minister Leona Aglukkaq told a news conference in Ottawa. Production will no longer be permitted in homes. Medical marijuana producers will have to apply to the health minister for licences and must undergo security clearances and quality-control inspections.
"Current medical marijuana regulations have left the system open to abuse," said Aglukkaq. "We have heard real concerns from law enforcement, fire officials and municipalities about how people are hiding behind these rules to conduct illegal activity, and putting the health and safety of Canadians at risk. These changes will make it far more difficult for people to game the system." - Laura Eggertson, CMAJ

CMAJ 2013. DOI:10.1503/cmaj.109-4528 